\title{
DEFINITION OF BOUNDARY CONDITIONS FOR THE NUMERICAL MODEL OF TRANSIENT TEMPERATURE FIELD OF A CONCAST STEEL SLAB
}

The solidification and cooling of a continuously cast billet, slab or cylinder (generally a concasting) is a very complicated problem of 3-D transient heat and mass transfer. This paper is focused on the derivation of boundary conditions, i.e. the values of the heat transfer coefficient (HTC) on all boundaries of the concasting machine (CCM). The definition of boundary conditions is the most difficult part of the investigation of the thermokinetics of this process. The boundary conditions in the numerical model of the temperature field of the concasting are defined as the heat transfer by convection. This HTC includes the so-called reduced convection coefficient corresponding to heat transfer by radiation. This paper therefore continues with a discussion on heat transfer coefficients under air-water cooling jets, which spray the concasting in the so-called secondary-cooling zone.

Keywords: Concast slab, boundary conditions, cooling characteristics

\section{Nomenclature}

$i_{v}$

$Q$

$Q_{\text {source }}$ internal heat source, W.m ${ }^{-3}$

$T \quad$ temperature, ${ }^{\circ} \mathrm{C}$

$V \quad$ volume, $\mathrm{m}^{3}$

$x, y, z \quad$ axes in given direction

w shift rate, $\mathrm{m} \cdot \mathrm{s}^{-1}$

$\lambda \quad$ heat conductivity, $\mathrm{W} \cdot \mathrm{m}^{-1} \cdot \mathrm{K}^{-1}$

$\tau \quad$ time, $\mathrm{s}$

$\rho \quad$ density, $\mathrm{kg} \cdot \mathrm{m}^{-3}$

\section{Introduction}

One of the more significant differences between a concasting machine (CCM) for the casting of billets and that for the casting of slabs (Fig. 1) is in the cooling within the secondary-cooling zone. This is due to the convection of a greater amount of heat from the voluminous slab casting, where the secondary-cooling zone in EVRAZ VITKOVICE STEEL is subdivided into thirteen sections. The first section engages water jets from all sides of the concasting. The remaining twelve sections engage air-water cooling jets, which are positioned only on the upper and underside of the concasting.
It is therefore very important to determine the correct boundary conditions for the numerical model of the temperature field [1-6].

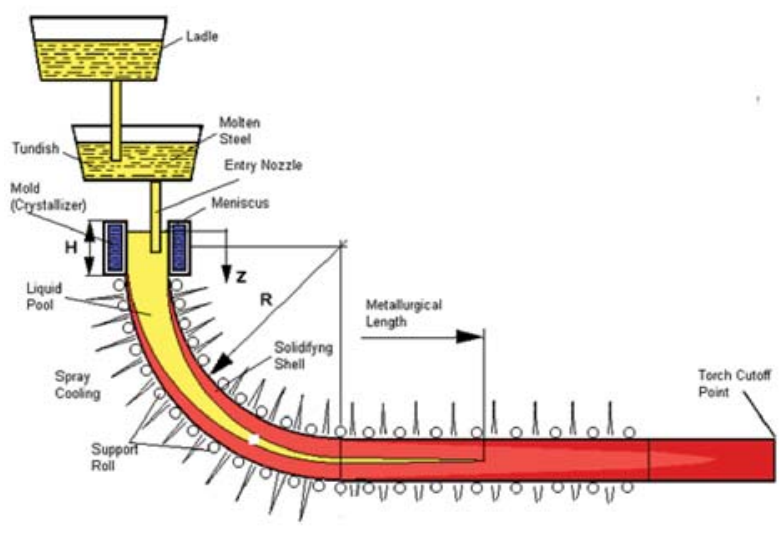

Fig. 1 A concasting machine (CCM)

\section{A numerical model of the temperature field of a slab}

The solidification and cooling of a concasting and simultaneous heating of the crystallizer is a very complicated problem of $3 \mathrm{D}$

\footnotetext{
${ }^{*}$ Frantisek Kavicka ${ }^{1}$, Josef Stetina ${ }^{1}$, Bohumil Sekanina ${ }^{1}$, Milos Masarik ${ }^{2}$

${ }^{1}$ Department of Power Engineering, Faculty of Mechanical Engineering, Brno University of Technology, Brno, Czech Republic,

E-mail: kavicka@fme.vutbr.cz

${ }^{2}$ EVRAZ VITKOVICE STEEL, a.s. Ostrava, Ostrava, Czech Republic
} 
transient heat and mass transfer. The 3D transient temperature field of the concasting, passing through the CCM (the zones of primary, secondary and tertiary cooling), can be described by the Fourier-Kirchhoff equation

$$
\begin{aligned}
& \frac{\partial T}{\partial \tau}=\frac{\lambda}{\rho \cdot c}\left(\frac{\partial^{2} T}{\partial x^{2}}+\frac{\partial^{2} T}{\partial y^{2}}+\frac{\partial^{2} T}{\partial z^{2}}\right)+ \\
& \left(w_{x} \frac{\partial T}{\partial x}+w_{y} \frac{\partial T}{\partial y}+w_{z} \frac{\partial T}{\partial z}\right)+\frac{Q_{\text {SOURCE }}}{\rho \cdot c}
\end{aligned}
$$

The derivation of the temperature by time becomes zero upon the reaching of the steady state. Equation (1), when considering movement in the direction of the z-axis only, can be simplified to

$$
\frac{\partial T}{\partial \tau}=a \cdot \Delta T+w_{z} \frac{\partial T}{\partial z}+\frac{Q_{\text {source }}}{\rho \cdot c}
$$

The 3D transient temperature field of a crystallizer cooled by water is expressed by the Fourier equation, i.e (2) without the member $w_{z}(\partial T / \partial z)$. The authors had chosen the explicit difference method, which enables the application of the most convenient method of numerical simulation of the release of latent heat of phase or structural changes using the thermodynamic enthalpy function. In order to describe the temperature field of a concasting in all its three stages, i.e. in: the melt $\rightarrow$ the mushy zone $\rightarrow$ the solid phase equation (2) must be converted to

$$
\frac{\partial i_{v}}{\partial \tau}=\lambda . \Delta T+w_{z} \frac{\partial i_{v}}{\partial z}+Q_{\text {source }}
$$

The specific volume enthalpy $i_{v}=c \cdot \rho \cdot T$ is dependent on temperature. The specific heat capacity $c$, density $\rho$ and heat conductivity $\lambda$ are also functions of temperature. The authors have developed an original numerical model [7], which solves the Fourier and Fourier-Kirchhoff equation. The program also takes into account the non-linearity of the task, i.e. the dependence of the thermophysical properties of all materials entering the system being investigated, and the dependence of the heat-transfer coefficients on all boundaries of the system on the temperature of the working surfaceof the concasting or crystallizer-and on other influences (e.g. shift rate, intensity of spraying). The exactness of the presented numerical model depends on the accuracy with which the thermophysical properties of the materials of all parts of the system are determined. These properties can be set either via a table or with the help of coefficients of approximation polynomials describing the curve [8].

\section{Definition of boundary conditions of solution}

Furthermore, the exactness of the numerical model depends on the derivation of boundary conditions. Therefore the setting of the properties is followed by the setting of the boundary conditions, i.e. the values of the heat transfer coefficient (HTC) on all CCM boundaries. The dependences of these coefficients on temperature and other operation parameters must also be given. The definition of boundary conditions is the most difficult part of the investigation of the thermokinetics of this process. The boundary conditions in the numerical model of the temperature field of the concasting are defined as the heat transfer by convection (Fig. 2).
This HTC includes the so-called reduced convection coefficient corresponding to heat transfer by radiation.

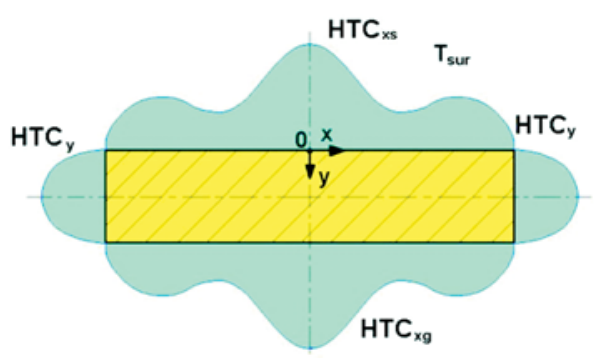

Fig. 2 Boundary conditions on the slab surface

For example the boundary condition of the slab-crystallizer interface depends on the thermophysical properties and the state of the casting powder, and also on the shape and size of the gap (Fig. 3).

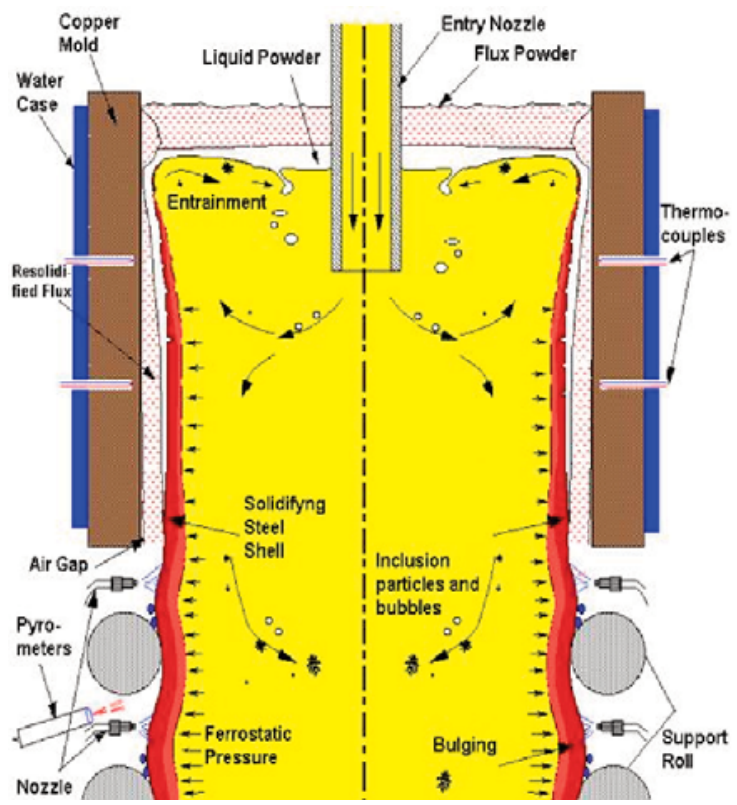

Fig. 3 The boundary condition of the slab-crystallizer interface

The only, but extremely important, coefficient, after leaving the crystallizer, is the HTC on the surface of the concasting, and is mainly dependent on the temperature of the surface, the shift rate and the intensity of spraying. This paper therefore continues with a discussion on heat transfer coefficients under air-water cooling jets, which spray the concasting in the so-called secondary-cooling zone. On a real CCM, where there are many types of jets with various settings positioned inside a closed cage, it is practically impossible to conduct measurement of the real boundary condi- 

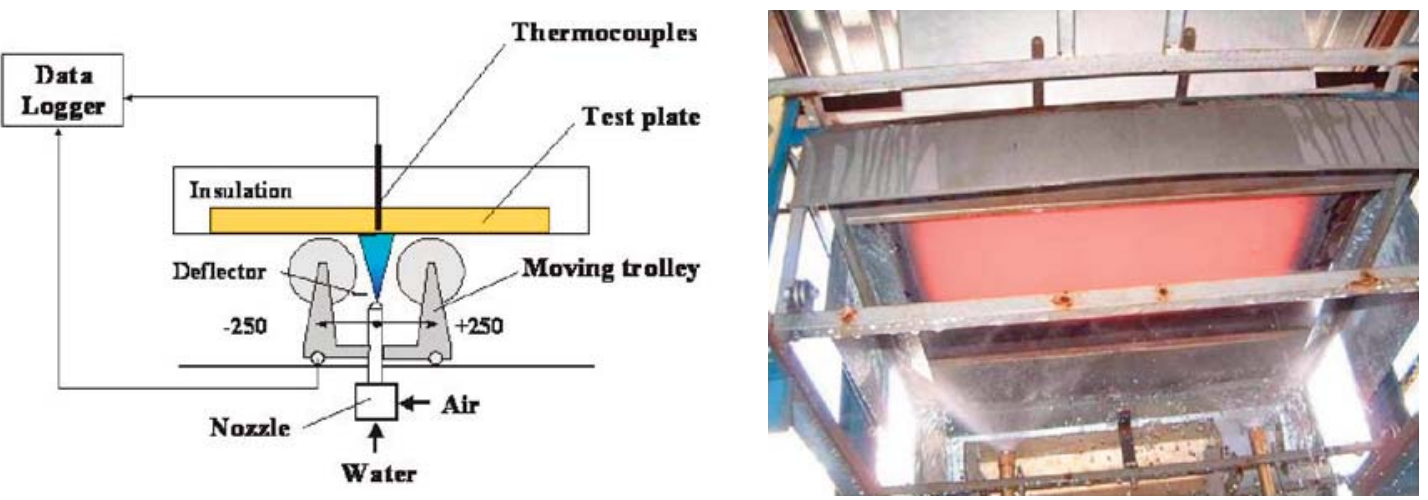

Fig. 4 Experimental laboratory device

tions. Therefore, a laboratory device was introduced in order to measure the cooling characteristics of the jets (Fig. 4). This experimental laboratory device simulates not only the movement, but also the surface of a slab. Real CCM contains a total 8 types of jets and geometrical layouts.

This laboratory device enables the measurement of each jet separately. It comprises a steel plate mounted with 18 thermocouples, heated by an external electric source. The steel plate is heated to the testing temperature, then it is cooled by a cooling jet. Based on the temperatures measured in dependence on time, the HTCs are calculated by an inverse task. They are then processed further using an expanded numerical and an identification model and converted to coefficients of the function $\operatorname{HTC}(T, y, z)$, which expresses the $H T C$ in dependence on the surface temperature, and also the position of the concasting with respect to the jet.

Figures 5 and 6 illustrate the area of influence of the cooling jet and the 3D course of the heat transfer coefficient under the cooling jet. Fig. 7 illustrates the $H T C$ in dependence on the surface temperature.

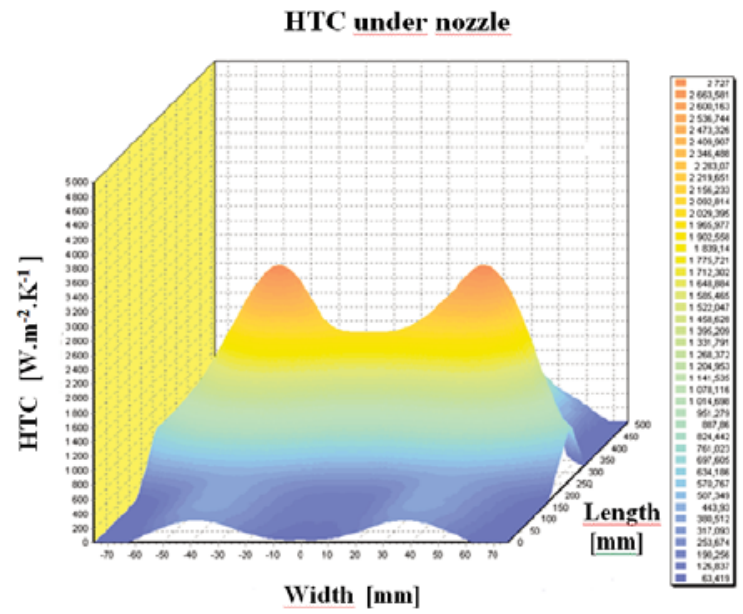

Fig. 5 3D diagram of HTC under the cooling jet
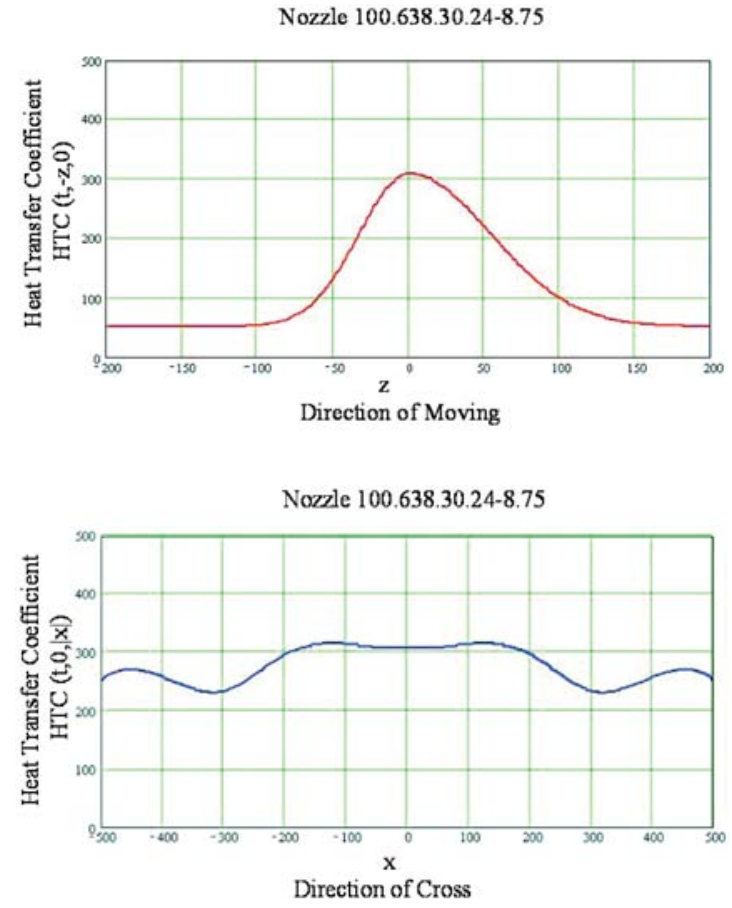

Fig. 6 The HTC for two directions under the cooling jet

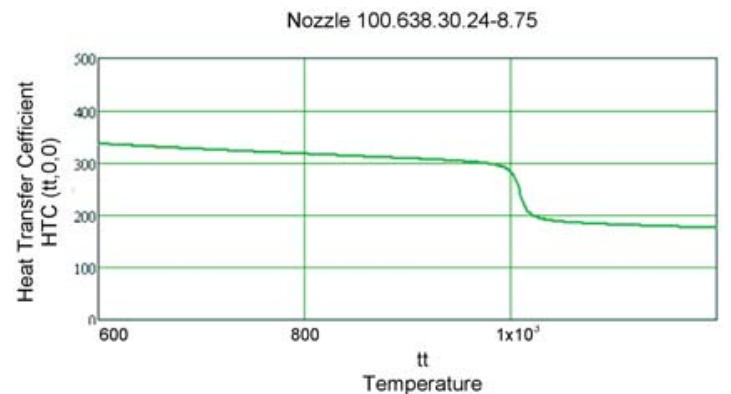

Fig. 7 The HTC in dependence on the surface temperature 


\section{Application of the numerical model on a concast steel slab}

The numerical model described above is applied in order to investigate a concast steel slab with a profile of $\mathrm{a} \times \mathrm{b}$ in any stage of the process, where a is the width ranging from 800 to $1600 \mathrm{~mm}$ and $b$ is the thickness ranging from 120 to $250 \mathrm{~mm}$ [ 9 and 10]. A diagram of the longitudinal section of the CCM for radial concasting was illustrated in Fig. 1.

It was decided to simulate the temperature field of a $1530 \times$ $\times 250 \mathrm{~mm}$ steel slab. The conditions of pouring were characterized by the temperature in the tundish $\left(1548{ }^{\circ} \mathrm{C}\right)$, by the temperature of the liquid $\left(1515{ }^{\circ} \mathrm{C}\right)$, by the temperature of the solidus $\left(1479{ }^{\circ} \mathrm{C}\right)$, and by the shift rate of the slab $\left(0.7 \mathrm{~m} \cdot \mathrm{min}^{-1}\right)$.

The maximum number of nodal points is $2.5 \times 10^{6}$ (Fig. 8), which could also be sufficient in order to cover a more complex cross section. Such a density of the net enables the linear interpolation of the temperatures among the points of the net, and also among the time sectors.

After the computation, it is possible to obtain the temperatures at each node of the network and at any time during the process. Very useful is the temperature history graph (Fig. 9), which shows the temperature at defined points of the cross-section of the slab. The course of the temperatures can also be displayed in any other user-defined point.

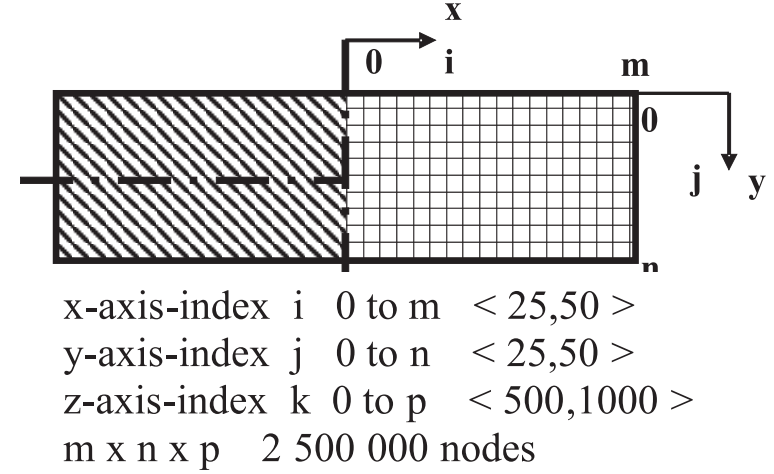

Fig. 8 The slab profile and the numerical network

Figure 9 illustrates the repetitive drops in temperature in the secondary-cooling zone, which are caused by the intensive cooling by jets. Each successive temporary increase in temperature, which is reflected in the saw-tooth character of the curve, is caused by the movement of the slab - the given point moves out of reach of the previous jet and passes through an unsprayed zone before it moves into the scope of the next jet in line. The vertical shaded band in Fig. 9 shows the range of depths (17-17.625 m) beneath the level of the melt in the crystallizer, within which the slab becomes completely solid. The radio-isotope measurement confirmed this so-called metallurgical length to be $17.4 \mathrm{~m}$.

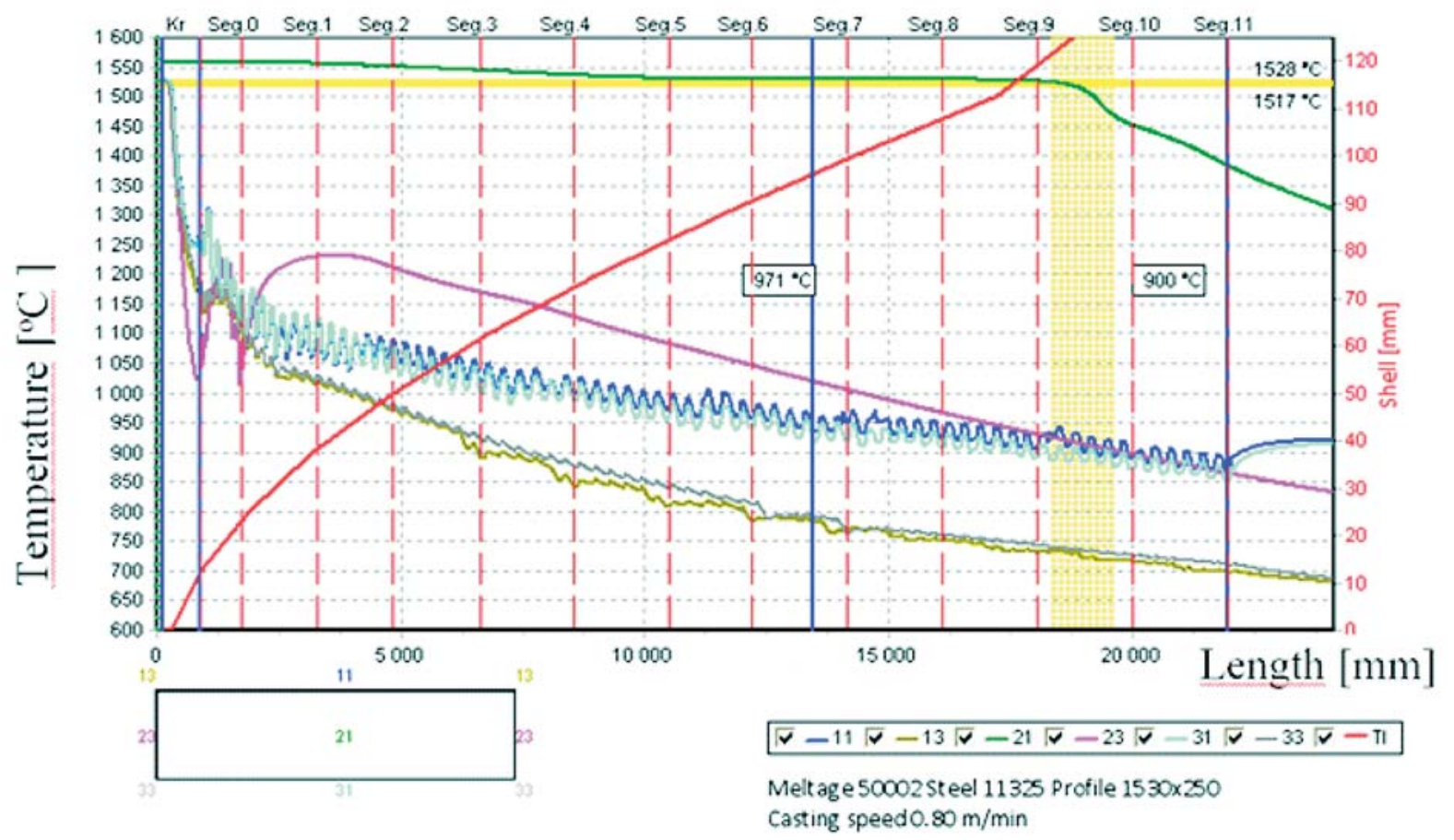

Fig. 9 The temperature history in the selected points of the cross-section 
The comparison of the computed and pyrometer-measured temperatures at a distance of $1000 \mathrm{~mm}$ beneath the level of the melt within the crystallizer proved that the model is appropriate.

\section{Conclusion}

The value of the $H T C$ coefficient on the surface of the slab, as it enters the secondary-cooling zone, significantly affects the process simulation from the viewpoint of the temperature field, the technological length, and also other technological properties. It therefore affects prediction of the quality of the slab.

In order to be able to simulate this boundary condition within the numerical model as accurately as possible, it is necessary to conduct experimental measurement on each jet in the secondarycooling zone individually.
Each of the eight jets had been measured separately on the hot model, on which the hot surface of the slab, which is cooled by a moving jet, can be modeled. The temperatures measured on the surface of the model can be entered into an inverse task to calculate the intensity of spraying, which, in turn, can determine the HTC by a special mathematical method.

These values (of the coefficients of all jets), which correspond satisfactorily with experimentally attained temperatures and technological length, have been successfully applied in the calculation of the temperature field of slabs.

\section{Acknowledgement}

This analysis was conducted using a program devised within the framework of the GA CR projects No 107/11/1566, 106/08/ 0606 and 106/09/0940.

\section{References}

[1] LECHNER, M., REITER, J., BERNHARD, C., FORSTHUBER, M., ZACH, O.: Bestimmung und Bedeutung der Randbedingungen fuer die Simulation von Stranggiesprozessen, BHM, 3, 2004, pp.101-106.

[2] RICHARD, A., HARDING, KAI LIU, BECKERMANN, CH.: A Transient Simulation and Dynamic Spray Cooling Control Model for Continuous Steel Casting. Metallurgical and Materials Transactions, vol. 34B, 2003, pp. 297-302.

[3] HORSKY, J., RAUDENSKY, M., TSENG A. A.: Heat Transfer Study of Secondary Cooling in Continuous Casting. AISTech 2005, Iron \& Steel Technology Conference and Exposition, 2005, Charlotte, USA.

[4] MAUDER, T. et al.: An Optimal Relationship between Casting Speed and Heat Transfer Coefficients for Continuous Casting Process. METAL 2011 Conference Proc. Papers Symp. A, Metal. Ostrava, Tanger. 2011. p. 42-48, ISBN 978-80-87294-24-6 (CD ROM Paper 649).

[5] PYSZKO, R., BURDA, J., FOJTIK, P., PRIHODA, M., CARNOGURSKA, M. Surface Condition for the Model of Strand Temperature field in the CCM Secondary Zone. Proc. of the XVIII. Intern. Sci. Conference The Application of Experimental and Numerical Methods in Fluid Mechanics and Energetics 2012. University of Zilina. Demanovska dolina, 2012, pp. 218-223. ISBN 978-80-554-0516-2

[6] CARNOGURSKA, M., PRIHODA, M., BRESTOVIC, T., MOLINEK, J., PYSZKO, R.: Determination of Permeability and Inertial Resistance Coefficient of Filter Inserts used in the Cleaning of Natural Gas. J. of Mechanical Sci. and Technology, vol. 26, No.1, pp. 103-111, 2012, ISSN 1738-494X, ISSN 1226-4865.

[7] STETINA, J.: A Dynamic Model of Temperature Field of Concast Steel Slab. PhD Thesis. VSB-TU Ostrava, Faculty of Metallurgy and Materials Engineering, Ostrava, 2007, p. 105.

[8] MIETTINEN, J., LOUHENKILPI,S., LAINE, J.: Solidification Analysis Package IDS. Proc. of General COST 512 Workshop on Modeling in Materials Science and Processing, M. Rappaz and M. Kedro eds., ECSC-EC-EAEC, Brussels, Luxembourg, 1996.

[9] KAVICKA F. et al.: The Optimization of a Concasting Technology by Two Numerical Models. J. of Materials Processing Technology 185 (2007), pp.152-159.

[10] STETINA, J. et al.: Optimization of a Casting Technology of a Steel Slab via Numerical Models. Proc. $22^{\text {nd }}$ Canadian Congress of Applied Mechanics, Dalhousie University Halifax, Nova Scotia, 2009, p. 4. 